\title{
Assessing PCB pollution in the Baltic Sea - An equilibrium partitioning based study
}

Lang, Susann-Cathrin; Mayer, Philipp; Hursthouse, Andrew; Kötke, Danijela; Hand, Ines; Schulz-Bull, Detlef; Witt, Gesine

\section{Published in:}

Chemosphere

Link to article, DOI:

10.1016/j.chemosphere.2017.10.073

Publication date:

2018

Document Version

Peer reviewed version

Link back to DTU Orbit

Citation (APA):

Lang, S-C., Mayer, P., Hursthouse, A., Kötke, D., Hand, I., Schulz-Bull, D., \& Witt, G. (2018). Assessing PCB pollution in the Baltic Sea - An equilibrium partitioning based study. Chemosphere, 191, 886-894.

https://doi.org/10.1016/j.chemosphere.2017.10.073

\section{General rights}

Copyright and moral rights for the publications made accessible in the public portal are retained by the authors and/or other copyright owners and it is a condition of accessing publications that users recognise and abide by the legal requirements associated with these rights.

- Users may download and print one copy of any publication from the public portal for the purpose of private study or research.

- You may not further distribute the material or use it for any profit-making activity or commercial gain

- You may freely distribute the URL identifying the publication in the public portal 


\section{Accepted Manuscript}

Assessing PCB pollution in the Baltic Sea - An equilibrium partitioning based study

Susann-Cathrin Lang, Philipp Mayer, Andrew Hursthouse, Danijela Kötke, Ines Hand, Detlef Schulz-Bull, Gesine Witt

PII: S0045-6535(17)31654-5

DOI: $\quad$ 10.1016/j.chemosphere.2017.10.073

Reference: CHEM 20095

To appear in: $E C S N$

Received Date: 13 June 2017

Revised Date: 9 October 2017

Accepted Date: 11 October 2017

Please cite this article as: Lang, S.-C., Mayer, P., Hursthouse, A., Kötke, D., Hand, I., Schulz-Bull, D., Witt, G., Assessing PCB pollution in the Baltic Sea - An equilibrium partitioning based study, Chemosphere (2017), doi: 10.1016/j.chemosphere.2017.10.073.

This is a PDF file of an unedited manuscript that has been accepted for publication. As a service to our customers we are providing this early version of the manuscript. The manuscript will undergo copyediting, typesetting, and review of the resulting proof before it is published in its final form. Please note that during the production process errors may be discovered which could affect the content, and all legal disclaimers that apply to the journal pertain. 


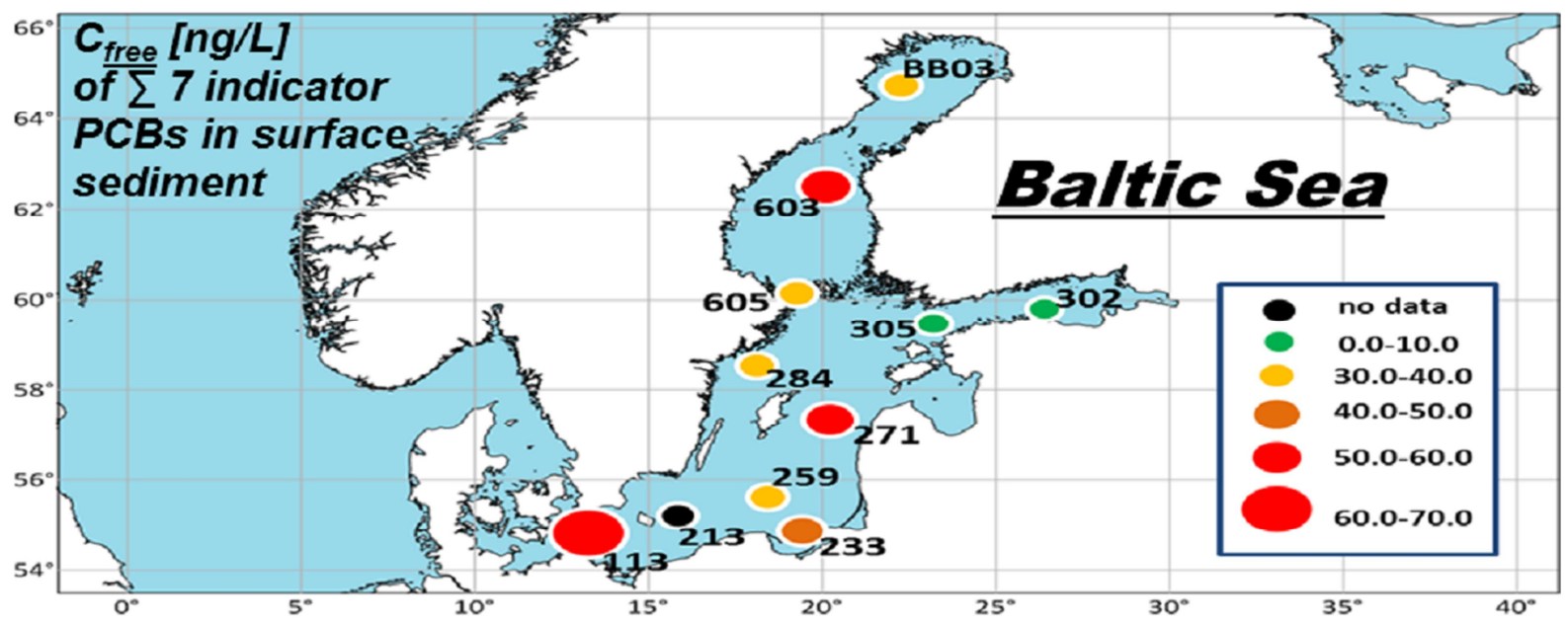




\section{Assessing PCB pollution in the Baltic Sea - an equilibrium}

\section{2 partitioning based study}

3

4 Authors' names

$5 \quad$ Susann-Cathrin Lang ${ }^{1,2,+*}$, Philipp Mayer $^{3}$, Andrew Hursthouse ${ }^{2}$, Danijela Kötke ${ }^{4}$, Ines

6 Hand $^{5}$, Detlef Schulz-Bull ${ }^{5}$, Gesine Witt ${ }^{1,+}$

\section{Authors' addresses}

$9{ }^{1}$ University of Applied Sciences Hamburg, Department of Environmental Engineering,

Ulmenliet 20, 21033 Hamburg, Germany

${ }^{2}$ Institute of Biomedical and Environmental Health Research, School of Science \& Sport, University of the West of Scotland, Paisley Campus, Paisley PA 1 2BE, United Kingdom

3 Technical University of Denmark, Department of Environmental Engineering, 2800 Kongens Lyngby, Denmark

${ }^{4}$ Helmholtz-Zentrum Geesthacht, Centre for Materials and Coastal Research, Institute of Coastal Research, Max-Planck-Strasse 1, 21502 Geesthacht, Germany

${ }^{5}$ Leibniz Institute for Baltic Sea Research, Seestraße 15, 18119 Rostock, Germany

${ }^{\ddagger}$ Corresponding author

* Present address: Agilent Technologies, Hewlett-Packard-Str. 8, 76337 Waldbronn, Germany

\section{Keywords}

passive sampling; bioavailability; sediments; PCBs; chemical activity; baseline toxicity 
26

27

\section{Abstract}

Sediment cores and bottom water samples from across the Baltic Sea region were analyzed for freely dissolved concentrations $\left(\mathrm{C}_{\text {free }}\right)$, total sediment concentrations $\left(\mathrm{C}_{\mathrm{T}}\right)$ and the dissolved aqueous fraction in water of seven indicator PCBs. Ex-situ equilibrium sampling of sediment samples was conducted with polydimethylsiloxane (PDMS) coated glass fibers that were analyzed by automated thermal desorption GC-MS, which yielded PCB concentrations in the fiber coating $\left(\mathrm{C}_{\text {PDMS }}\right)$. Measurements of $\mathrm{C}_{\mathrm{PDMS}}$ and $\mathrm{C}_{\mathrm{T}}$ were then applied to determine (i) spatially resolved freely dissolved PCB concentrations; (ii) baseline toxicity potential based on chemical activities (a); (iii) site specific mixture compositions; (iv) diffusion gradients at the sediment water interface and within the sediment cores; and (vi) site specific distribution ratios $\left(\mathrm{K}_{\mathrm{D}}\right)$. The contamination levels were low in the Gulf of Finland and moderate to elevated in the Baltic Proper, with the highest levels observed in the western Baltic Sea. The SPME method has been demonstrated to be an appropriate and sensitive tool for area surveys presenting new opportunities to study the in-situ distribution and thermodynamics of hydrophobic organic chemicals at trace levels in marine environments.

\section{Introduction}

The Baltic Sea as a shallow semi-enclosed sea is connected to the open ocean through the North Sea. The mean residence time of the sea water is between 25 and 40 years (Rheinheimer, 1996). This facilitates the accumulation of pollutants in the Baltic Sea, because only $2-3 \%$ of the contaminants entering can flow out through the North Sea (Brügmann, 1993). Large parts of the catchment area are industrialised or in agricultural use. The coastal zone of the southern Baltic Sea is strongly influenced by anthropogenic inputs derived from industry, agriculture, tourism and shipping (Blanz et al., 1999). In addition, atmospheric 
deposition from the catchment area and non-Europe countries, due to long-range transport of pollutants in air, seriously reinforces the level of contamination of the Sea. Kot-Wasik et al., (2004), reported that in the middle of the 1980s approximately $30000 \mathrm{t} \mathrm{a}^{-1}$ of chlorinated organic compounds were discharged into the Baltic Sea from pulp mills. HELCOM identified 162 hot-spots in the Baltic Sea region (1992), with 110 being removed to date. However, their past pollution load was often buried in soils or sediments and has not yet disappeared from the ecosystem (HELCOM, 2010).

The environmental sensitivity and the strong anthropogenic pressures of the region have been recognized by the littoral states for many decades (Janßen et al., 2013). In response, the European Union Marine Strategy Framework Directive (MSFD) aims to establish effective protection of the EU's marine waters by putting in place a common framework for marine policy. The main objective of the MSFD is to achieve or maintain a good environmental status (GES) of the EU's marine waters by 2020, which corresponds closely to the declared aims of the HELCOM Baltic Sea Action Plan (Ahtiainen et al., 2013). Since 1990, the main goal of HELCOM has been to re-establish ecological equilibrium conditions. The general situation is that, HELCOM identified decreasing contamination trends for a variety of compounds, but with residual accumulation still present (Liehr, 2006). The Baltic Sea Action Plan was adopted by the coastal countries and the European Community in November 2007; as a regional intergovernmental program, it introduces measures to protect and manage the marine environment based on the Ecosystem Approach. Thus, ecological objectives are used to define indicators and targets, effect-based nutrient input and monitor implementations (Backer et al., 2010).

Polychlorinated biphenyls (PCBs) are ubiquitous anthropogenic contaminants. They are widely distributed in the environment through, for example, inappropriate handling of waste material or leakage from transformers, condensers and hydraulic systems (HELCOM, 2013). They are still emitted into the atmosphere via vaporization and open burning of products 
containing PCBs (U.S.EPA, 2007) due to their production and application worldwide. Even though PCB manufacture was banned in the 1980s (U.S.EPA, 2014), their release into the environment is still a challenge. PCB concentrations decline only very slowly in soils and sediments due to their high persistency and high sorption to the soil and sediment matrix (Rein et al, 2007). Once accumulated mainly in the lipid-rich tissue of organisms, PCBs have been shown to cause cancer and several serious non-cancer health effects (U.S. EPA, 2007). For that reason, PCBs are defined as priority pollutants by the U.S. EPA (U.S. EPA, 2012) and are included in the 2002 by OSPAR adopted list of chemicals for priority action (OSPAR, 2013).

Assessments of HOCs and their risks have traditionally been based on total concentrations of contaminants in the sediment, which are poorly related to the bioavailability and toxicity of these pollutants (Mayer et al., 2014). Potential risks of adverse biological effects from sediment associated contaminants are better related to concentrations of freely dissolved chemicals in the sediment porewater (effective concentrations) (Mayer et al., 2014). Today it is known that the contaminant's total amount in the sediment is not a suitable measure since it addresses neither of the two aspects of bioavailability defined by Reichenberg and Mayer (2006): (1) Accessibility: The quantity of the contaminant in the system which can be made available for an organism (i.e. the fraction which is not "trapped" in the environmental matrix). (2) Chemical activity/fugacity: The contaminant's thermodynamic potential for spontaneous physicochemical processes such as partitioning between different compartments in an environmental system, including partitioning into biological tissues (bioaccumulation).

It has been shown that measurements of $C_{\text {free }}$, rather than their estimations using generic $K_{d}$ values, can significantly improve the prediction of bioaccumulation (You, Landrum and Lydy, 2006; Mayer et al, 2014). Kraaij et al. (2003) predicted for instance internal concentrations of a few model HOCs in Tubificidae (benthic oligochaetes) as product of $\mathrm{C}_{\text {free }}$ and bioconcentration factors. The strong agreement with measured biota concentrations 
confirmed that bioaccumulation was the result of partitioning (not excluding oral uptake as an exposure route).

The measurement of $\mathrm{C}_{\text {free }}$ or chemical activity (a) gives direct information about the direction of the diffusive mass transfer, which always takes place from areas of high to low $\mathrm{C}_{\text {free }}$ concentration and chemical activity (Reichenberg and Mayer, 2006). Chemical activities in environmental media can be calculated by dividing $\mathrm{C}_{\text {free }}$ of a sparingly soluble compound in water by its respective subcooled liquid solubility $\left(\mathrm{S}_{\mathrm{L}}\right)$ (Schwarzenbach et al., 2003).

A number of studies have been carried out to investigate PCB sediment concentrations. Nevertheless, studies are mostly restricted to specific regions in the Baltic Sea and only a few studies have been investigating freely dissolved concentrations of PCBs in sediment porewaters applying different types of passive sampling techniques (e.g. Cornelissen et al, 2008; Jahnke et al., 2012). The major advantages of passive sampling over "classical methods" are the simple sample preparation and considerably low detection limits especially regarding the highly hydrophobic substances that are enriched from water to polymer by 3-7 orders of magnitude. Passive sampling techniques are environmentally "green", i.e. they are time and cost efficient and less resource lavish.

The aim of this study was to comprehensively investigate exposure, fate, partitioning, bioavailability, and baseline toxicity of selected PCBs. The study also makes substantial contribution to the assessment of sediment characteristics in terms of providing the first largescale investigation of seven PCBs using an equilibrium sampling approach in Baltic Sea sediments. We identified (i) large scale horizontal gradients of $\mathrm{C}_{\text {free }}$ and chemical activity; (ii) gradients of diffusion within sediment cores as well as at the sediment-water interface; (iii) site specific distribution ratios $\left(\mathrm{K}_{\mathrm{D}}\right)$ and (iv) the baseline toxic potential. The approach used in this study provides a novel strategy to assess HOC contaminated sediments. It extends conventional approaches and techniques currently applied and delivers distinct insights in comparison to results obtained with classical analytical methods. 


\section{Experimental section}

130 Sampling

131 Baltic Sea sediment cores were sampled in June and July 2008 during a cruise on the research

132 vessel "Maria S. Merian". The cores were obtained using a sediment multi corer and cut into

$1332 \mathrm{~cm}$ thick slices on board. The samples were homogenized and aliquots were stored at $-18{ }^{\circ} \mathrm{C}$

134 in pre-cleaned aluminum boxes and polyethylene (PE) containers until they could be 135 analyzed. A total core with a length of $20 \mathrm{~cm}$ was sampled from eleven stations. Bottom water 136 was sampled with the Kiel in-situ pump system (KISP, Aimes, Kiel, Gemany) described by 137 Petrick et al. (1996). KISP was fixed on a wire and lowered to preselected depth. After six 138 hours of sampling approximately $360 \mathrm{~L}$ was processed and HOCs collected onto a XAD-2 139 resin column. The loaded column was stored cool and dark until analysis. (For further 140 information of the sampling procedure please refer to text S6 (SI)). Hydrographical-chemical 141 parameters were obtained with a CTD rosette. A map showing the sampling locations is given 142 in figure S1 (SI). Details, geographical positions and sampling depth of the stations are 143 presented in SI, table S1.

\section{Chemicals and other materials}

146 A list of all materials and chemicals used as well as a description for treatment of glassware, 147 solvents and other materials are given in text S1 (SI) and S2 (SI), respectively.

\section{Bulk sediment analyses}

150 The water content and the total organic carbon content (TOC) were determined for all 151 sediment samples. In addition, black carbon (ROC) was measured for surface sediments. Text 152 S3 (SI) describes the procedures. 
154

155

156

157

158

159

160

161

162

163

164

165

166

167

168

169

170

171

172

\section{Chemical analyses of sediment and bottom water}

The sediment samples were analyzed for freely dissolved and total PCB sediment concentrations $\left(\mathrm{C}_{\mathrm{T}}\right)$ using equilibrium sampling and exhaustive extractions to yield concentrations for the seven indicator PCBs (PCB 28, 52, 101, 118, 138, 153 and 180). Figure 1 presents the analytical procedure of sediment processing as a flow chart.

Solid phase micro-extraction (matrix-SPME) (Witt et al., 2009) was carried out to determine sediment porewater concentrations. The fibers were analyzed with a GC-MS system (7890A GC, 5975C MSD, Agilent Technologies) equipped with a cold injection system (CIS) for thermal desorption of the fibers and a GERSTEL Automated Liner EXchange system (ALEX) for fully automated sample processing. Calculated freely dissolved concentrations were temperature corrected from $20{ }^{\circ} \mathrm{C}$ (laboratory) to $4{ }^{\circ} \mathrm{C}$ (field) using the Van't Hoff equation and actual fiber coating thicknesses were measured with laser scanning confocal technology. A detailed description of the analytical procedure (SPME experiments, GC-MS analyses, measurement and calculation of $\mathrm{C}_{\text {free }}$ as well as important requirements) is given in the Text S4 (SI).

Total sediment concentrations were determined by application of accelerated solvent extraction (ASE) to the sediment samples, followed by a SPE (solid phase extraction) cleanup of the extract and subsequent analyses via GC-MS. The analytical procedure is described in text S5 (SI).

Dissolved bottom water PCB concentrations were analyzed by extracting the loaded XAD-2 columns with solvents, a subsequent clean-up step and measurement of the compounds of interest with GC-MS. A precise summary of the analytical procedure is presented in text S6 (SI).

\section{Quality control and assurance $(\mathrm{QA} / \mathrm{QC})$ :}


Method validation was performed by assessing measurement precision (10 times replicate of a standard solution), linearity (multipoint calibration, 3 replicates) and system solvent blanks of the analytical system. Evaluation of processing blanks, repeatability of the sample processing procedure (reference material and sample), recovery rates of the analytes (based on internal standard processing) and accuracy (standard reference sediment) were used to predict final uncertainty of the analytical results.

Precision of the measurement method was determined with $<10 \%$ for uncorrected and ISTD (internal standard) corrected area responses for the 7 PCBs. Linear regression of the calibration curves yielded coefficients of determination $\left(\mathrm{R}^{2}\right)>0.990$ and target PCBs were not detected in solvent blanks.

Method detection and quantification limits of the optimized methods (MDLs and MQLs) were calculated using the average PCB target responses in processing blanks plus 3 times (MDL) or 10 times (MQL) the standard deviation. MQLs were between 5 and $18 \mathrm{pg} \mu \mathrm{L}^{-1}$ PDMS for PCBs. MDLs were lower than $10 \mathrm{pg} \mu \mathrm{L}^{-1}$ PDMS for all target compounds. Final mean standard recoveries of internal and external PCB target compounds of standard test solutions were $90 \% \pm 15 \%$. For an average of eight sediment samples being extracted via ASE one blank was processed and analyzed simultaneously. Mean standard recoveries of the internal standard solutions added to each sample were calculated for all target compounds with $82 \% \pm$ 7\%. Additionally, the standard reference materials EC-4 as well as QPH 058 and QPH 059 (QUASIMEME, Laboratory Performance Studies, http://www.quasimeme.org/) were equally processed with the samples and checked for recovery. The measured concentrations for the single compounds were in all cases in the range of certified values ( \pm certified uncertainty). 
Sediment core samples of Baltic Sea $(20 \mathrm{~cm})$<smiles>[Te]</smiles>

\section{Homogenization of slices $(10 \times 2 \mathrm{~cm})$ \\ $\downarrow 5$ g aliquot, wet \\ $5 \mathrm{~g}$ aliquot, wet}

Fiber experiment

(matrix-SPME)

\section{(Accelerated solvent extraction (ASE))}

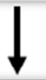

3 fibers (ca. $10 \mathrm{~cm}$ ) were directly inserted into the sediment slurry at $20^{\circ} \mathrm{C}$ until equilibrium was reached

\section{Fiber retrieval and cleaning}

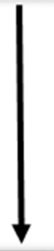

Analyses of 7 PCBs with GC-MSD

Thermal desorption of the SPME fiber

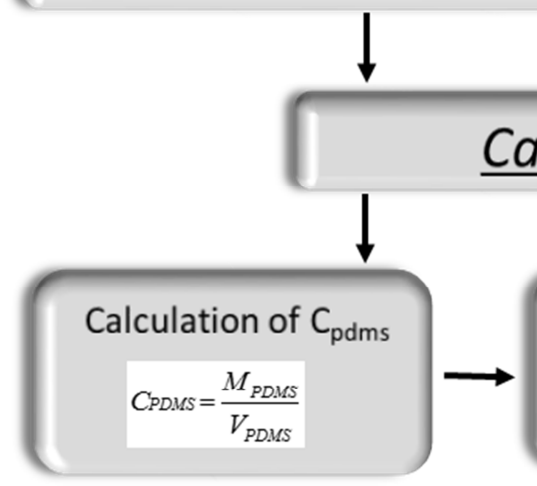

\section{Calculation of concentrations}

Figure 1: Diagram presenting the steps of the analytical procedure of sediment processing.

$$
C_{\text {free }}=\frac{C_{P D M S}}{K_{P D M S}}
$$
copper
Solid-phase extraction (SPE) with a solvent conditioned doubled Baker-Bond column filled with $3 \mathrm{~g}$ of deactivated aluminum oxide (top) and silica (bottom)

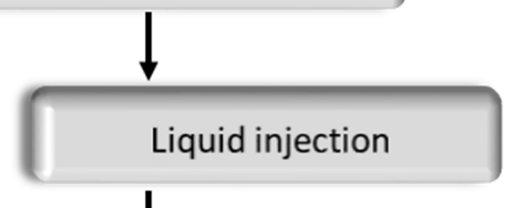

Concentration of the solvent extract to $<500 \mu \mathrm{L}$

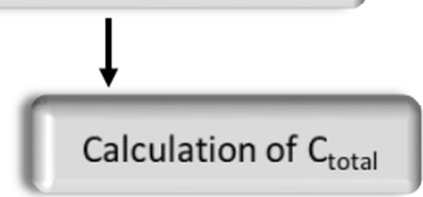


The TOC content of Baltic Sea sediment cores ranged from 1.4\% - 11.5\% (w/w, dry).

Concomitant with progressive diagenesis at greater sediment depths, i.e. the decomposition of its mineralization, a decrease of TOC was observed. Average TOC values from the measured triplicates for each sampling station and depth are presented in detail in Table S2 (SI).

Besides TOC, black carbon (ROC) is suggested to play a major role in the sorption of hydrophobic organic contaminants (Jonker and Koelmans, 2002; Lohmann et al., 2005;

Cornelissen et al., 2005; Staniszewska et al., 2011). Depending on the measurement method and definition the TOC can be interpreted to include the two components ROC and OC (organic carbon) fraction, i.e. OC + ROC $=$ TOC (Accardi-Dey and Gschwend, 2002). ROC contents ranged between $0.043 \%$ and $0.225 \%$ (w/w, dry) for the sediment layer of $2-4 \mathrm{~cm}$ (individual values can be found in the SI). Jahnke et al. (2012) determined the ROC to be approximately $0.2 \%$ in surface sediments of the Stockholm Archipelago after applying the method of Gustafsson et al. (1997) for soot quantification, which closely corresponds to the data from the Åland Sea (605) recorded herein.

Composition of the sum of $\mathbf{C}_{\text {free }}$ in surface sediments and spatial distribution

The most hydrophobic PCBs (CB 118 - CB 180) yielded very low concentrations compared to the less hydrophobic PCBs (CB 28 - 101). The PCB distribution pattern was similar among the sampling stations (see Box-plot, Figure 2). CB 28 and 52 yielded markedly higher variability of $\mathrm{C}_{\text {free }}$ for the sediment depth $0-2 \mathrm{~cm}$ in contrast to the other PCBs. For CB 118 an outlier was observed at the Bothnian Bay (site BB03). CB 101 concentrations were notably lower at the Gulf of Finland (site 302 and 305) compared to the other stations. Box-plots of PCB distribution patterns and therefore $\mathrm{C}_{\text {free }}$ concentration ranges for all sediment depths at the eleven investigation sites are given in figure S2 (SI). 
232 Jahnke, et al (2012), studied freely dissolved concentrations in surface sediments along an E-

$233 \mathrm{~W}$ transect from central Stockholm towards the outer Stockholm Archipelago (in the region of

234 site 605 (Åland Sea)) and found decreasing trends in this direction. Their results for 7 PCB

235 congeners are in good agreement with the data presented in this study. Within congener

236 concentration variability, in some cases CB 28 and CB 52 were up to 3 - 7 higher in this study

237 and for CB 101, 118, 153, 138 and 180 up to 10 times higher in their study. The lower

238 concentrations of the higher chlorinated PCBs at the Åland Sea were consistent with their

239 decreasing trends towards the open Baltic Sea.

240

241 Distribution of $\mathbf{C}_{\text {free }}$ in sediment cores 
ACCEPTED MANUSCRIPT
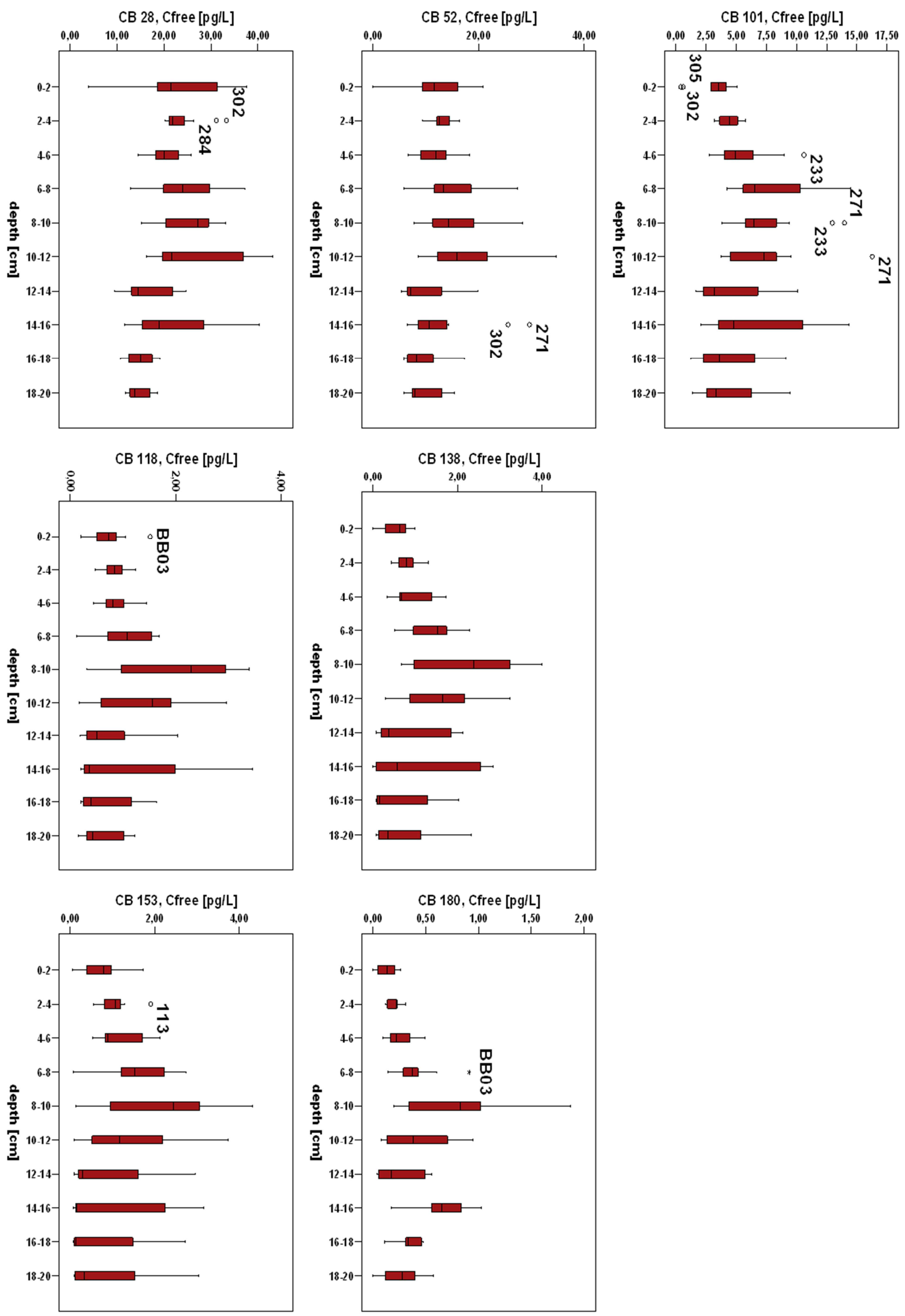

242

12 
243 Figure 2: Box-plots for the 7 measured PCBs as depth profiles, including the $\mathrm{C}_{\text {free }}$

244 concentration values [pg L $\mathrm{p}^{-1}$ ] for all sampling stations of the Baltic Sea in each box. Each box

245 displays the median, the 10-, 25-, 75- and 90-percentile as well as the extreme value (asterisk)

246 and outlier (circle) for the compound of interest.

248 Figure 2 displays box-plots as depth profiles for the 7 PCBs, including the $\mathrm{C}_{\text {free }}$ data for all 249 Baltic Sea sampling stations in each box. Highly elevated freely dissolved PCB 250 concentrations were mainly found in deeper sediment layers $(8-16 \mathrm{~cm})$. Since PCB

251 manufacture was banned around the 1980s, a rapidly decreasing environmental concentration 252 could be expected to be reflected in the upper sediment layers by lower concentrations. Even 253 though their release in the environment is on-going through burning of PCB containing 254 products and strong environmental persistence. In most cases PCBs were not elevated in the upper sediment layers. However, increasing concentration levels towards the upper sediment layers were observed for PCBs in the northern Baltic Sea. A clear increase was observed for station 603 (Bothnian Sea), whereas slightly elevated $\mathrm{C}_{\text {free }}$ levels were found at the Bothnian Bay (BB03) for CB 101 and CB 118. Individual depth profiles for the sediment cores and measured PCBs are displayed in figure S3 (SI).

\section{Baseline toxicity}

The sum of chemical activities, calculated from the single $\mathrm{C}_{\text {free }}$ values of the individual compounds is an indicator of the baseline toxic potential of a mixture (Di Toro et al., 2000).

Baseline toxicity, also referred to as narcosis, is the minimal toxicity a single compound can cause when crossing membranes (Escher and Schwarzenbach, 2002). Mixtures can include thousands of individual compounds and even if all these compounds are below the threshold level of specific toxicity, the underlying cumulative baseline toxicity might determine the overall toxic effect (Escher et al., 2002). 
In this study baseline toxicity or rather the contribution to the baseline toxicity potential of a mixture was evaluated for the sum of seven PCBs. The PCB mixture showed moderate variations between the sites and was below lethality in any case. In most cases the contribution of the sum of PCBs to the baseline toxic potential was approximately a factor of thousand below the effective activity range (EA50, between 0.01 and 0.1 ). At this chemical activity range baseline toxicity is lethal (Reichenberg and Mayer, 2006).

Values for the sum of chemical activities (seven PCBs) for all sediment depths at the sampling stations and the mean, maximum and minimum value for each station are presented in table 3 (SI). Within the sediment cores the highest chemical activities were mostly found in the middle or deeper sediment layers, suggesting that an organism experiences lower exposure from PCBs in surface sediment layers. Depth profiles of the sum of chemical activities of the seven PCBs for all sampling stations can be found in figure S4 (SI).

\section{Comparison of the composition of $\mathrm{C}_{\text {free }}$ and chemical activity}

A comparison of the variation in molecular composition of the $7 \mathrm{PCBs}$ as a percentage of $\mathrm{C}_{\text {free }}$ and chemical activity for station BB03 at a sediment depth of $0-2 \mathrm{~cm}$ is given in Figure 3 . Although the percentage composition of $\mathrm{C}_{\text {free }}$ and chemical activity varied moderately between the sampling stations, the general distribution of the PCBs was consistent for a depth of $0-2 \mathrm{~cm}$. Lower chlorinated PCBs had only a minimal contribution to the chemical activity and therefore to baseline toxicity. In contrast, higher chlorinated PCBs which contributed less to $\mathrm{C}_{\text {free, }}$, predominated the contribution to the overall exposure when expressed as chemical activity. This example clearly demonstrates the relevance of not only freely dissolved concentrations, but also on the properties of a single compound when assessing baseline toxicity from chemical activities of a contaminant mixture. Thus, the baseline toxicity of PCB mixtures is not only controlled by the concentration but also by the properties and characteristics of the individual compounds. In this context, it is relevant to be mentioned, 
that freely dissolved PCBs concentrations were found to be 2 - 3 orders of magnitude lower than PAHs concentrations (Lang et al., 2015). Nevertheless, the sum of chemical activities and hence the contribution to the baseline toxic potential was only one order of magnitude lower for PCBs compared to PAHs.

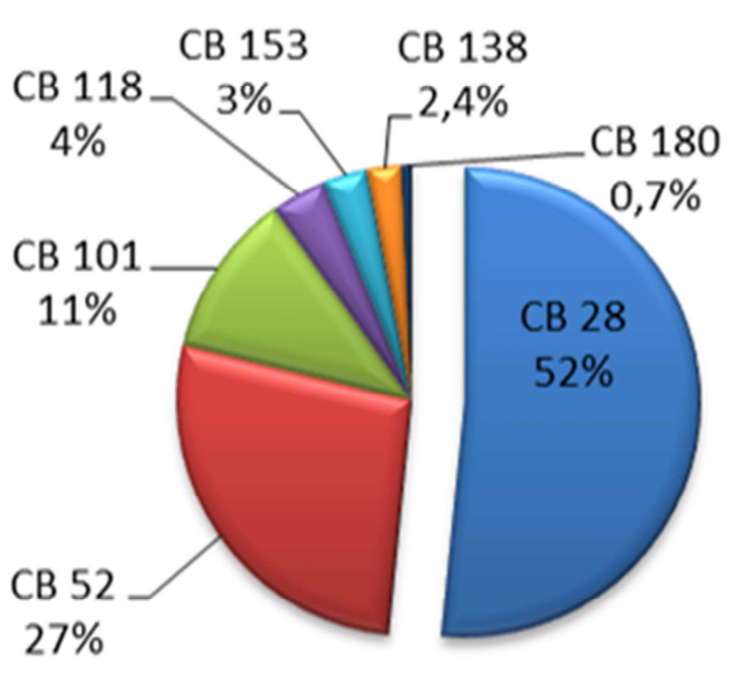

\section{$\mathrm{C}_{\text {free }}, \mathrm{BB03}$}

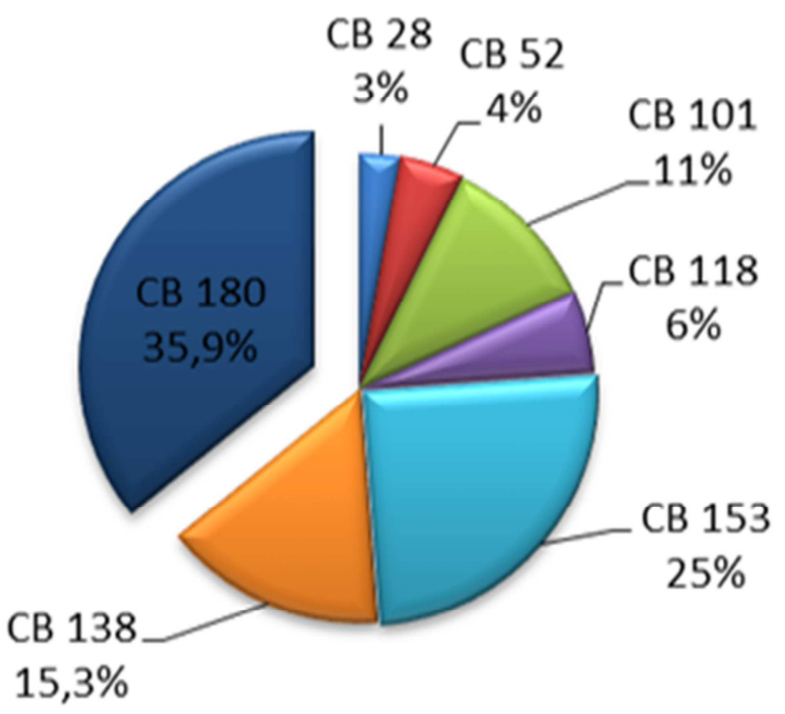

chemical activity, BB03

Figure 3: Comparison between the contributions of 7 individual PCBs to $\mathrm{C}_{\text {free }}$ and chemical activity in percentage for the surface sediment layer $(0-2 \mathrm{~cm})$ at site BB03 (Bothnian Bay, Baltic Sea).

\section{Diffusion gradients}

An indicator for diffusive mass transfer of contaminants is also the chemical activity (Reichenberg and Mayer, 2006). Diffusion always takes place from high to low chemical activity. Diffusion gradients, i.e. the direction of contaminant mass transfer in the sediment can be seen in the vertical profiles of the chemical activities. In addition, the diffuse mass transfer at the sediment water interface was investigated for PCBs to address the question whether the Baltic Sea sediments act as diffusive source or as diffusive sink to the water column. 
312 Figure 4 displays the activity profiles of the sum of seven PCBs for site 113 (Arkona Sea),

313305 (Gulf of Finland) and 605 (Åland Sea). The black arrows indicate the direction of

314 contaminant diffusion within the depth profile from high to low chemical activity. PCB

315 activity profiles for the other stations without indicative arrows are given in figure S4 (SI) and

316 individual values in table S3 (SI).

317 Station 113 represents a profile determined by a low range of chemical activities over the 318 entire depth and therefore low diffusion gradients. Site 305 (Gulf of Finland) showed a 319 maximum chemical activity at a sediment layer of $6-8 \mathrm{~cm}$ and a diffusion trend towards the 320 upper and deeper sediment layers. Site 605, represents a diffusion pattern directed to mid 321 sediment layers and was not observed at any other site. Profiles with low variations in 322 chemical activities were also found for stations 213, 233 and 259. All other stations revealed a clearly identifiable maximum in middle up to deeper sediment layers with a varying diffusion trend towards upper and deeper sediment layers.

113

$1, \mathrm{E}-07 \quad 1, \mathrm{E}-06 \quad 1, \mathrm{E}-05 \quad 1, \mathrm{E}-04 \quad 1, \mathrm{E}-03 \quad 1, \mathrm{E}-02 \quad 1, \mathrm{E}-01 \quad 1, \mathrm{E}+00$

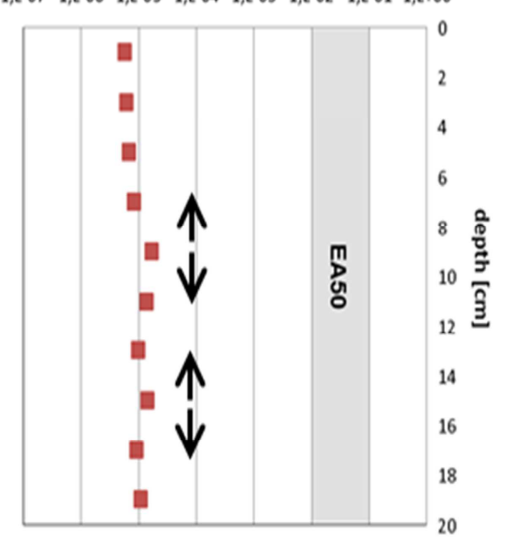

305

$1, \mathrm{E}-07 \quad 1, \mathrm{E}-06 \quad 1, \mathrm{E}-05 \quad 1, \mathrm{E}-04 \quad 1, \mathrm{E}-03 \quad 1, \mathrm{E}-02 \quad 1, \mathrm{E}-01 \quad 1, \mathrm{E}+00$

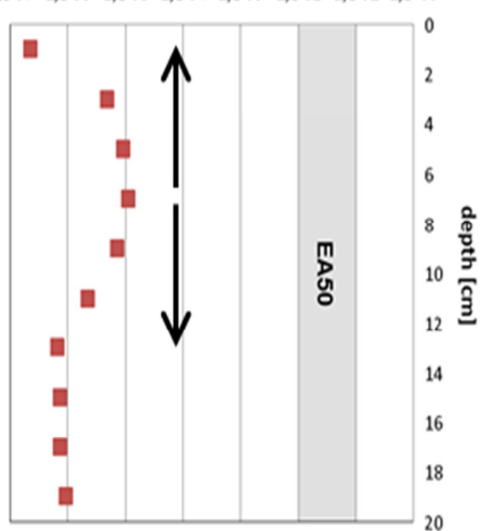

605 chemical activity, sum 7 PCBs

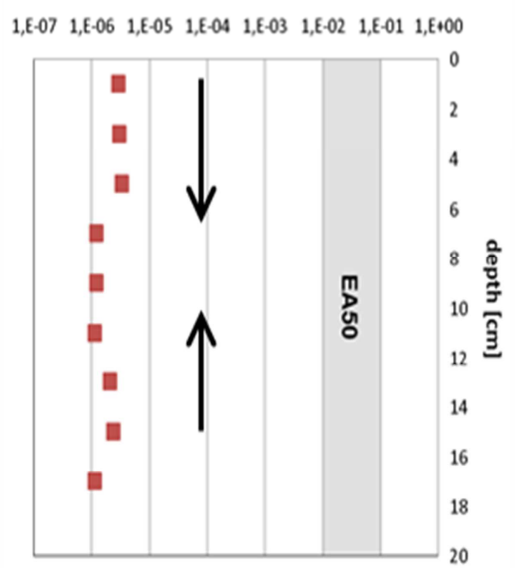

Figure 4: Vertical profiles of the sum of chemical activities for three Baltic Sea sampling sites $(113,305$ and 605) calculated from seven PCBs for each depth. Small and large black arrows indicate small-scale and overall diffusion trends, respectively. 
Sediment to water activity ratios: Chemical activities of sediment porewater (surface layer,

$0-2 \mathrm{~cm}$ depth) were plotted against chemical activities of the bottom water for PCBs (figure

S5 (SI)). Calculated activity ratios ( $\left.\mathrm{a}_{\mathrm{PW}} / \mathrm{a}_{\mathrm{BW}}\right)$ between sediment porewater $(\mathrm{PW})$ and bottom

water (BW) indicate whether sediments act as diffuse source or sink. The grey line in the diagrams indicates similar activities $\left(\mathrm{a}_{\mathrm{PW}} / \mathrm{a}_{\mathrm{BW}}=1\right)$ in sediment porewater and bottom water, which implies a similar energetic state between these compartments where no spontaneous diffusion processes occur. A ratio of $\mathrm{a}_{\mathrm{PW}} / \mathrm{a}_{\mathrm{BW}}>1$ suggests that the sediment acts as a source of PCBs to the water body, while a ratio of $\mathrm{a}_{\mathrm{PW}} / \mathrm{a}_{\mathrm{BW}}<1$ suggests that the sediment acts as a sink.

In a few cases the chemical activities of the 7 PCBs were almost equal (thermodynamic equilibrium, $\mathrm{a}_{\mathrm{PW}} / \mathrm{a}_{\mathrm{BW}}=1$ ) or lower (disequilibrium, $\mathrm{a}_{\mathrm{PW}} / \mathrm{a}_{\mathrm{BW}}<1$ ) in the sediment compared to the chemical activities in the bottom water. Exceptional diffusive flux, directed from water to sediment ( $\mathrm{a}_{\mathrm{PW}} / \mathrm{a}_{\mathrm{BW}}$ : 0.26 - 1.04) were found at site 302 and 305 (Gulf of Finland) for CB 118, CB 138 and CB 153 and at station 284 (Western Gotland Sea) for CB 180 and the sediment was assumed to act as a sink. In all other cases the ratios were: $a_{\mathrm{PW}} / \mathrm{a}_{\mathrm{BW}}>1$, which implies the sediment to act as a diffuse source for PCBs. Calculated chemical activity ratios of sediment porewater to bottom water (apw/a $/ \mathrm{a}_{\mathrm{BW}}$ ) for the seven different PCBs at the 11 sampling stations are given in table $\mathrm{S} 4(\mathrm{SI})$.

In a previous study (Cornelissen et al., 2008), mean $\mathrm{a}_{\mathrm{PW}} / \mathrm{a}_{\mathrm{BW}}$ ratios close to one were calculated for $14 \mathrm{PCBs}$ at five locations in the open northern Baltic Sea region. They concluded equilibrium conditions between sediment porewater and overlying water in the open Baltic Sea, which implies no overall diffusive flux of PCBs. Further, Jahnke et al reported higher chemical activities of PCBs in lake and Baltic Sea sediment compared to biota and water (Jahnke et al, 2012; Jahnke et al, ES\&T 2014; Jahnke et al, ESPI 2014 ). 
It is also known that black carbon (ROC, a part of the TOC) - like organic carbon - is an important sorbent for PCBs in the Baltic Sea (Gustafsson et al., 1997; Gustafsson et al., 2001; Cornelissen and Gustafsson, 2005b). ROC was measured in addition to TOC, to investigate its impact on the sorption behavior of the compounds in Baltic Sea sediments. An assessment of correlation between $\mathrm{K}_{\mathrm{D}}$ values $\left(=\mathrm{C}_{\mathrm{T}} / \mathrm{C}_{\text {free }}\left[\mathrm{L} \mathrm{Kg}^{-1} \mathrm{dw}\right]\right)$ and $\mathrm{ROC}$ as well as TOC yielded positive results. The $\mathrm{K}_{\mathrm{D}}$ values were plotted against TOC and ROC and regional differences of the sorption capacity and sorptive strength of the sediments were identified. $K_{\mathrm{D}}$ values and plots of $\mathrm{K}_{\mathrm{D}}$ against TOC and ROC for individual PCBs can be found in table S5 (SI) and in figure S7 (SI), respectively.

A strong correlation with TOC was found for all PCBs in the northern Baltic Sea region $\left(\mathrm{R}^{2}\right.$ : 0.84 - 0.94). In contrast, a moderate correlation with ROC was observed $\left(R^{2}: 0.46-0.82\right)$ for this region. The correlation with ROC was also lower and inverse compared to TOC, suggesting that the major sorbent for PCBs is TOC in the northern Baltic Sea region. Jahnke et al. (2012) confirmed TOC as the major sorbent for PCBs in the Stockholm harbor and Archipelago, with $\mathrm{R}^{2}$ values between $0.49-0.70$ for six PCBs. Compared to the northern Baltic Sea region, the southern Baltic Sea region yielded low to moderate correlation coefficients between $K_{D}$ values and both TOC and ROC. The $R^{2}$ values between TOC and $K_{D}$ ranged from $0.05-0.89$, but with CB 101, 138 and 180 showing $\mathrm{R}^{2}$ values $<0.1$ and $\mathrm{CB} 28$, $52,118,153 \mathrm{R}^{2}$ values between 0.52 and 0.89 . In contrast, $\mathrm{R}^{2}$ values for $\mathrm{ROC}$ and $\mathrm{K}_{\mathrm{D}}$ ranged between $0.004-0.74$, with CB 28, 52 and 118 showing $\mathrm{R}^{2}$ values $<0.22$ and $\mathrm{CB} 101,138$, $153,180 \mathrm{R}^{2}$ values between 0.61 and 0.74 . For this region, the correlation with ROC was also inverse, but reverse of that in the northern Baltic Sea region. The results for the southern Baltic Sea region suggest a compound dependent sorption to ROC and TOC. CB 28, 52, 118 and 153 are more likely associated with TOC and CB 101, 138, 153 and 180 are more closely associated with ROC, while CB 153 showed similar $\mathrm{R}^{2}$ values with TOC and ROC. In the case of PCBs, station 271 (Gotland Deep) did not associate with any regional trends. With 
very high TOC content $(11.1 \%)$ and the highest $\mathrm{K}_{\mathrm{D}}$ values across all sites it remained exceptional.

An earlier study presented by Konat and Kowalewska (2001) showed trends and fate of PCBs in sediments of the southern Baltic, identifying main sources of contamination as floods and heavy rains washing these compounds from land to the sea, while PCB pollution is not directly attributable to specific human activity. Further they concluded that algae and algal detritus play an important role in the transport and distribution of PCBs in the southern Baltic, because of high correlation of PCBs with chlorophyll as derivatives. The northern Baltic Sea region in contrast, was directly influenced by industrial PCB discharge, before hot spots in this area were controlled (HELCOM, 2012 and 2013).

In a PCB survey of the U.S. EPA (2007) difference between urban and rural atmospheric pollution by PCBs was observed. The higher chlorinated PCBs, typically associated with the particle phase, were found at higher concentration in urban sites, whereas at rural sites, the PCB mixture had more PCB congeners with lower chlorination, typically associated with the gas phase. The distinct origin and input of PCBs between the two regions may explain the differences in sorption behaviour to TOC and ROC in general, whereas the northern Baltic Sea region could be described as dominated by rural inputs in contrast to the urban and industrial influenced southern Baltic Sea.

A plot of $\mathrm{K}_{\mathrm{D}}$ against $\mathrm{K}_{\mathrm{OW}}$ (Figure S6 (SI)) gives evidence of higher sorption strength of the sediments in the western Baltic Sea and Baltic Proper compared to the Gulf of Finland and northern Baltic Sea. The sediments of the Gotland Deep (station 271) have highest sorption strength for PCBs compared to all other sites. At the northern Baltic Sea region, highest $\mathrm{K}_{\mathrm{D}}$ values were observed for station BB03. Compared to site 603 and 605, station BB03 showed a higher TOC content and sediment concentrations, while $\mathrm{C}_{\text {free }}$ was only slightly elevated. In the Gulf of Finland, station 305 revealed only slightly higher $K_{D}$ values than site 302 and 
freely dissolved concentrations were similar at both sites. However, total sediment concentrations were approximately double compared to those at site 305 , while the TOC content was nearly half of the one at site 302. Thus, this would suggest that PCBs are more available for partitioning into the porewater at site 302 , while the sorption strength is higher at site 305. In the southern Baltic Sea region lowest $K_{D}$ values were observed at the Gdansk Deep (233). Compared to site 113, 213 and 259, total sediment concentrations were lowest, while $\mathrm{C}_{\text {free }}$ was similar for all stations indicating lower sorption strength and therefore a possibly higher bioavailability of the sediment bound PCBs in this region.

\section{Conclusions}

This study provides the first comprehensive dataset on freely dissolved concentrations and contaminant chemical activities of PCBs in Baltic Sea sediments. The SPME ALEX GC-MS method used for this basin-scale investigation proved to be a suitable and efficient tool to measure $\mathrm{C}_{\text {free. }}$ The method is straightforward provided some application conditions are considered. Measurements of $\mathrm{C}_{\text {free }}$ from seven indicator PCBs at the main sedimentation basins of the Baltic Sea allowed for the investigation of spatial gradients among and within the sites. Furthermore, the baseline toxic potential was successfully assessed. Highly hydrophobic substances were characterized by rather low levels for $\mathrm{C}_{\text {free }}$ and high levels of chemical activity. This means that whilst the contribution of such substances to the pool of freely dissolved molecules is often negligible, their contribution to the baseline toxic potential may be of high relevance. Moreover, this study clearly shows that $\mathrm{C}_{\text {free }}$ and chemical activity are important exposure parameters for expressing bioavailability and predicting baseline toxicity and physico-chemical processes like diffusion. The obtained results can be directly applied within a quantitative thermodynamic exposure assessment framework. On this basis, the presented results should be considered when assessing environmental risk and remedial 
PBDEs, PAHs and BFRs. It seems especially relevant to estimate and sum-up the contribution of mixture constituents to the baseline toxicity of complex mixtures, including priority pollutants as well as other hydrophobic chemicals. Reproducing and linking freely dissolved concentrations of HOC mixtures measured in the sediment pore-water to aquatic toxicity testing via passive dosing (Smith et al. 2010a, Smith et al. 2010b, Schmidt et al., 2013) which ensures constant exposure concentrations in bioassays over time, allows then for an ecotoxicological assessment under nearly `true` field conditions.

\section{Acknowledgement}

We like to thank the German Research Council (DFG) for funding the project and Robin Ernst, Tanja Prüfer and Erika Trost for their valuable assistance in the laboratory. We also thank the captain and crew of the RV Maria S. Merian for their support during the sample campaign.

\section{References}

Accardi-Dey, A. and Gschwend, P.M. (2002), “Assessing the combined roles of natural organic matter and black carbon as sorbents in sediments”, Environmental Science \& Technology, Vol. 36, pp. 21-29.

Ahtiainen, H., Artell, J., Czajkowski, M., Hasler, B., Hasselström, L., Hyytiäinen, K., Meyerhoff, J., Smart, J.C., Söderqvist, T., Zimmer, K., Khaleeva, J., Rastrigina, O. and Tuhkanen, H. (2013), "Public preferences regarding use and condition of the Baltic Sea-An international comparison informing marine policy”, Marine Policy, Vol. 42, pp. 20-30. 
Backer, H., Leppänen, J.M., Brusendorff, A.C., Forsius K., Stankiewicz, M., Mehtonen, J., Pyhälä, M., Laamanen, M., Paulomäki, H., Vlasov, N. and Haaranen, T. (2010), "HELCOM Baltic Sea Action Plan - A regional programme of measures for the marine environment based on the ecosystem approach", Marine Pollution Bulletin, Vol. 60, pp. 642-649.

Blanz, T., Schulz-Bull, D., Emeis, K., Petrick, G. and Duinker, J. (1999), “Chlorobiphenyls in suspension and sediment of the southern Baltic Sea: a mass balance calculation since the onset of PCB-production”, Continental Shelf Research, Vol. 19, pp. 891-910.

Brügmann, L. (1993), “Meeresverunreinigungen”, Akademie Verlag, Berlin, pp. 294.

Cornelissen, G., Wiberg, K., Broman, D., Arp, H. P. H., Persson, Y., Sundqvist, K. and Jonsson, P. (2008), "Freely dissolved concentrations and sediment-water activity ratios of PCDD/Fs and PCBs in the open Baltic Sea”, Environmental Science \& Technology, Vol. 42, , pp. $8733-8739$.

Cornelissen, G., Gustafsson, Ö., Bucheli, T.D., Jonker, M.T.O., Koelmans, A.A. and van Noort, P.C.M. (2005), "Extensive sorption of organic compounds to black carbon, coal, and kerogen in sediments and soils: mechanisms and consequences for distribution, bioaccumulation, and biodegradation", Environmental Science \& Technology, Vol. 39, pp. $6881-6895$.

Di Toro, D.M., McGrath J.A. and Hansen, D.J. (2000), “Technical basis for narcotic chemicals and polycyclic aromatic hydrocarbon criteria I. Water and tissue”, Environmental Toxicology and Chemistry, Vol. 19, pp. 1951-1970. 
Escher, B.I. and Schwarzenbach, R.P. (2002), "Mechanistic studies on baseline toxicity and uncoupling of organic compounds as a basis for modelling effective membrane concentrations in aquatic organisms", Aquatic Science, Vol. 64, pp. 20-35.

Escher, B.I., Eggen, R.I.L., Schreiber, U., Schreiber, Z., Vye, E., Wisner, B. and Schwarzenbach, R.P. (2002), "Baseline toxicity (Narcosis) of organic chemicals determined by in vitro membrane potential measurements in energytransducing membranes", Environmental Science \& Technology, Vol. 36, pp. 1971-1979.

Gustafsson, Ö, Bucheli, T. D., Kukulska, Z., Andersson, M., Largeau, C., Rouzaud, J.-N., Reddy, C. M. and Eglinton, T. I. (2001), "Evaluation of a protocol for the quantification of black carbon in sediments", Global Biogeochemical Cycles, Vol. 15, pp 881-890.

Gustafsson, O., Haghseta, F., Chan, C., McFarlane, J. and Gschwend, P. M. (1997), "Quantification of the dilute sedimentary soot phase: Implications for PAH speciation and bioavailability", Environmental Science \& Technology, Vol.31, pp. 203-209.

HELCOM (2013), “HELCOM Core Indicator of Hazardous Substances Polychlorinated biphenyls (PCB) and dioxins and furans”, http://helcom.fi/Core\%20Indicators/HELCOMCoreIndicator_Polychlorinated_biphenyls_and_dioxins_and_furans.pdf\#search=contaminants \%20in\%20sediment (2015-07-23).

HELCOM (2012), "Land based pollution group”, http://meeting.helcom.fi/c/document_library/get_file?p_1_id=18983\&folderId=1745451\&nam e=DLFE-49641.pdf (2015-07-23). 
511

512

513

514

515

516

517

518

519

520

521

522

523

524

525

526

527

528

529

530

531

532

533

534

535

536

HELCOM (2010), "Hazardous substances in the Baltic Sea”, BSEP120B - Baltic Sea

Environment Proceedings No. 120B, http://www.helcom.fi/Lists/Publications/BSEP120B.pdf (2015-07-23).

Jahnke, A., MacLeod, M., Wickström, H. and Mayer, P. (2014) ), “Equilibrium Sampling to

Determine the Thermodynamic Potential for Bioaccumulation of Persistent Organic

Pollutants from Sediment”, Environmental Science and Technology, Vol. 48, pp.

$11352-11359$.

Jahnke, A., Mayer, P., McLachlan, M.S., Wickström, H., Gilbert, D. and MacLeod, M.

(2014), "Silicone passive equilibrium samplers as 'chemometers' in eels and sediments of a

Swedish lake”, Environmental Science Processes \& Impacts, Vol.16, pp 464-472.

Jahnke, A., Mayer, P. and McLachlan, M.S. (2012), "Sensitive equilibrium sampling to study polychlorinated biphenyl disposition in Baltic Sea sediment”, Environmental Science \& Technology, Vol. 46, pp. 10114-10122.

Janßen, H., Kidd, S. and Kvinge, T. (2013), “A spatial typology for the sea: A contribution from the Baltic", Marine Policy, Vol. 42, pp. 190-197.

Jonker, M.T.O. and Koelmans, A.A. (2002), "Extraction of Polycyclic Aromatic

Hydrocarbons from soot and sediment: Solvent evaluation and implications for sorption mechanism”, Environmental Science \& Technology, Vol. 36, pp. 4107-4113.

Konat, J. and Kowalewska, G. (2001), "Polychlorinated biphenyls (PCBs) in sediments of the southern Baltic Sea — trends and fate", The Science of The Total Environment, Vol. 280, pp. $1-15$. 
538 Kot-Wasik, A., Dębska, J. and Namieśnik, J. (2004), “Monitoring of organic pollutants in 539 coastal waters of the Gulf of Gdańsk, Southern Baltic", Marine Pollution Bulletin, Vol. 49, 540 pp. 264-276.

542 Kraaij, R., Mayer, P., Busser, F.J.M., van het Bolscher, M., Seinen, W., Tolls, J. and Belfroid, 543 A.C. (2003), "Measured pore-water concentrations make equilibrium partitioning work a data analysis”, Environmental Science \& Technology, Vol. 37, pp. 268-274.

Lang, S.-C., Hursthouse, A., Mayer, P., Kötke, D., Hand, I., Schulz-Bull, D., Witt, G. (2015).

Equilibrium passive sampling as a tool to study polycyclic aromatic hydrocarbons in Baltic

Sea sediment pore-water systems. Marine Pollution Bulletin 101, 296-303.

Liehr, G.A. (2006), “Distribution and Ecotoxicological Effects of Polycyclic Aromatic Hydrocarbons (PAHs) in Sediments from the Western Baltic Sea”, PhD Dissertation, University of Rostock, Germany, pp. 137.

Lohmann, R., MacFarlane, J.K. and Gschwend, P.M. (2005), "Importance of black carbon to sorption of native PAHs, PCBs, and PCDDs in Boston and New York harbor sediments", Environmental Science \& Technology, Vol. 39, pp. 141-148. 
564 OSPAR (2013), “OSPAR List of Chemicals for Priority Action (Revised 2013)”,

565

566

567

568

569

570

571

572

573

574

575

576

577

578

579

580

581

582

583

584

585

586

587

http://www.ospar.org/content/content.asp?menu=00940304440050_000000_000000 (2015-

01-25).

Petrick, G., Schulz-Bull, D., Martens, V., Scholz, K. and Duinker, J. (1996), “An in-situ

filtration/extraction system for the recovery of trace organics in solution and on particles

tested in deep ocean water", Marine Chemistry, Vol. 54, pp. 97-105.

Reichenberg, F. and Mayer, P. (2006), “Two complementary sides of bioavailability:

Accessibility and chemical activity of organic contaminants in sediments and soils",

Environmental Toxicology and Chemistry, Vol. 25, pp. 1239-1245.

Rheinheimer, G. (1996), “Meereskunde der Ostsee”, Springer Verlag Berlin, 2. Auflage, pp. 338.

Staniszewska, M., Burska, D., Sapota, G., Bogdaniuk, M., Borowiec, K., Nosarzewska, I. and Bolałek, J. (2011), “The relationship between the concentrations and distribution of organic pollutants and black carbon content in benthic sediments in the Gulf of Gdańsk, Baltic Sea”, Marine Pollution Bulletin, Vol. 62, pp. 1464-1475. 
U.S. EPA (2014), “Technical Factsheet on: POLYCHLORINATED BIPHENYLS (PCBs)”, http://www.epa.gov/ogwdw/pdfs/factsheets/soc/tech/pcbs.pdf(2014-12-05).

591

592

U.S. EPA (2012), “Appendix A to 40 CFR, Part 423--126 Priority Pollutants”,

http://www.epa.gov/region1/npdes/permits/generic/prioritypollutants.pdf (2015-07-23).

594

Rein, A. Fernqvist, M., Mayer, P., Trapp, S., Bittens, M. and Karlson, U. 2007. Degradation of PCB congeners by bacterial strains - Determination of kinetic parameters and considerations for the modelling of rhizoremediation", Applied Microbiology and Biotechnology, Vol. 77, pp. 469-481.

599

600

Witt, G., Liehr, G.A., Brock, D. and Mayer, P. (2009), "Matrix solid-phase microextraction 601 for measuring freely dissolved concentrations and chemical activities of PAHs in sediment

602 cores from the western Baltic Sea”, Chemosphere, Vol. 74, , pp. 522-529.

603 assessing bioavailability of sediment-associated contaminants", Environmental Science \& Technology, Vol. 40, , pp. 6348-6353.

607 Chemical Research in Toxicology, Vol. 23, pp. 55-65. exposure of hydrophobic organic compounds in aquatic toxicity testing by passive dosing", Aquatic Toxicology, Vol. 98, pp. 15-24. 
615

616 Schmidt, S.N., Holmstrup, M., Smith, K.E.C. and Mayer, P. (2010b), "Passive dosing of

617 polycyclic aromatic hydrocarbon $(\mathrm{PAH})$ mixtures to terrestrial springtails: Linking mixture

618 toxcicity to chemical activities, equilibrium lipid concentrations, and toxic units",

619 Environmental Science \& Technologie, Vol. 47, pp. 7020-7027.

620 


\section{List of figure captions of the main manuscript:}

Figure 1: Diagram presenting the steps of the analytical procedure of sediment processing.

Figure 2: Box-plots for the 7 measured PCBs as depth profiles, including the $\mathrm{C}_{\text {free }}$ concentration

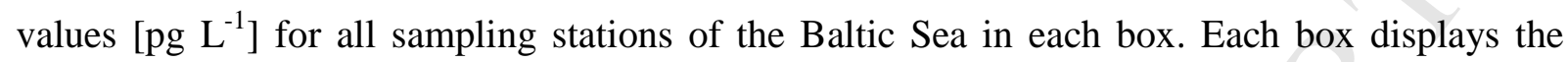
median, the 10-, 25-, 75- and 90-percentile as well as the extreme value (asterisk) and outlier (circle) for the compound of interest.

Figure 3: Comparison between the contributions of 7 individual PCBs to $C_{\text {free }}$ and chemical activity in percentage for the surface sediment layer $(0-2 \mathrm{~cm})$ at site BB03 (Bothnian Bay, Baltic Sea).

Figure 4: Vertical profiles of the sum of chemical activities for three Baltic Sea sampling sites $(113,305$ and 605) calculated from seven PCBs for each depth. Small and large black arrows indicate small-scale and overall diffusion trends, respectively. 


\section{Sediment core samples of Baltic Sea $(20 \mathrm{~cm})$}

\section{Homogenization of slices $(10 \times 2 \mathrm{~cm})$}

$\downarrow 5$ g aliquot, wet

\section{Fiber experiment} (matrix-SPME)

3 fibers (ca. $10 \mathrm{~cm}$ ) were directly inserted into the sediment slurry at $20^{\circ} \mathrm{C}$ until equilibrium was reached
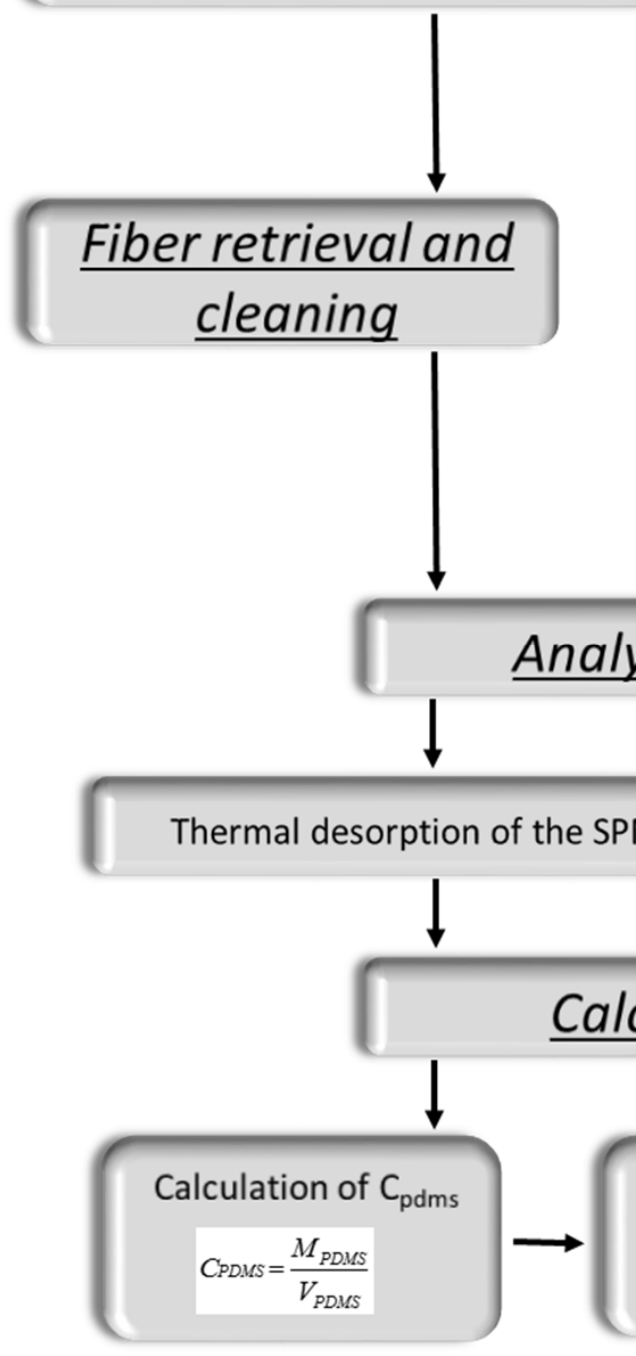

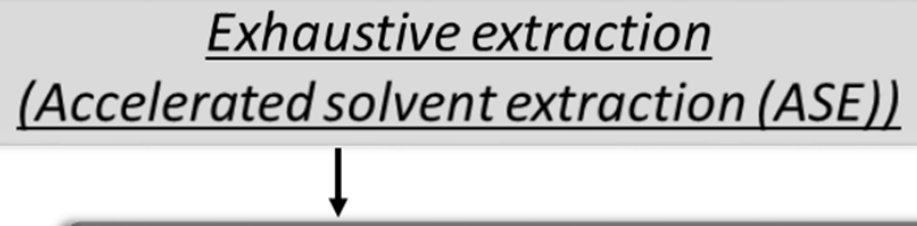

Water removal with $4 \mathrm{~g}$ anhydrous sodium sulphate

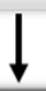

Sulphur removal with $4 \mathrm{~g}$ cleaned and acid-activated copper

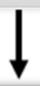

Solid-phase extraction (SPE) with a solvent conditioned doubled Baker-Bond column filled with $3 \mathrm{~g}$ of deactivated aluminum oxide (top) and silica (bottom)

\section{Concentration of the solvent extract to $<500 \mu \mathrm{L}$}

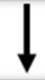



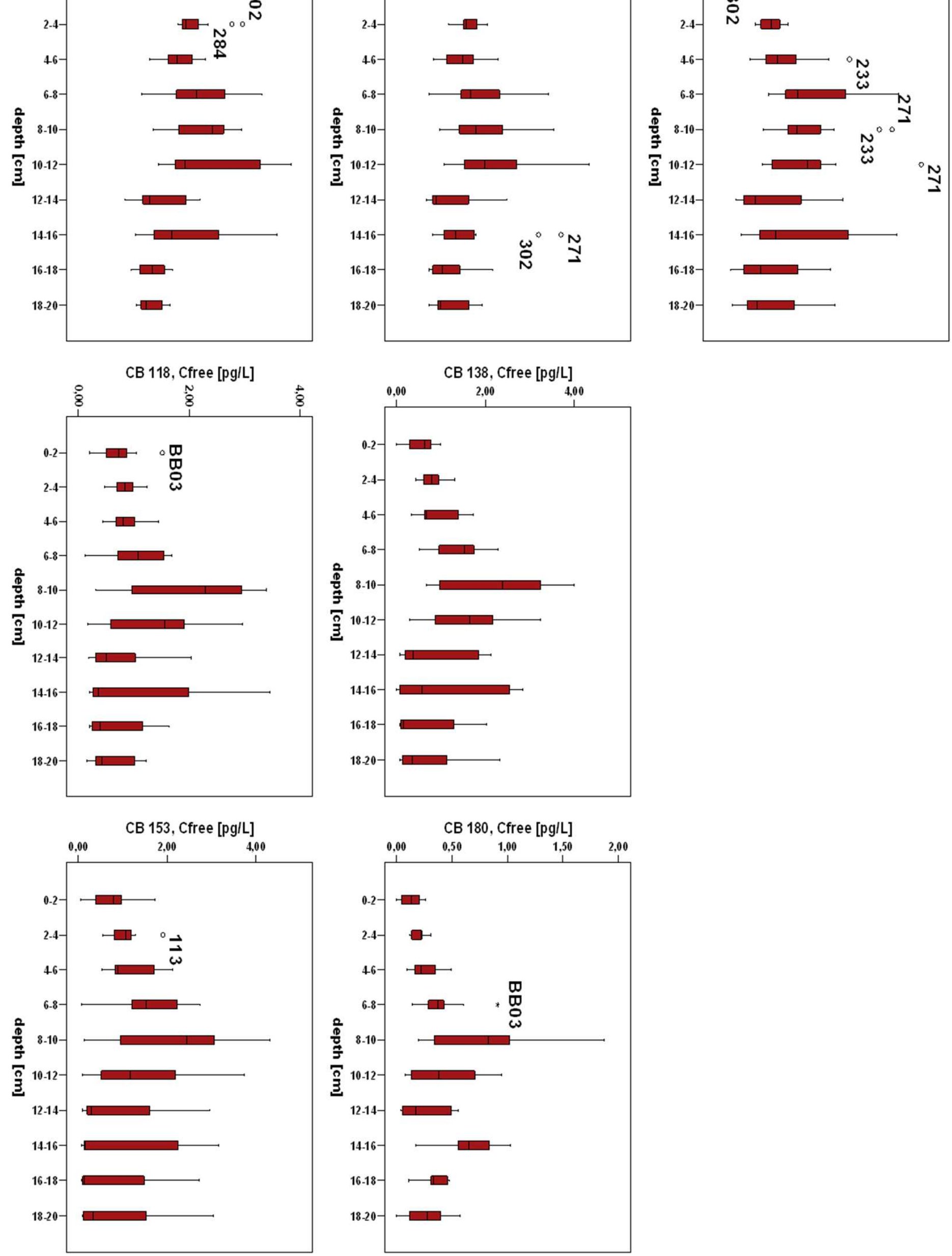

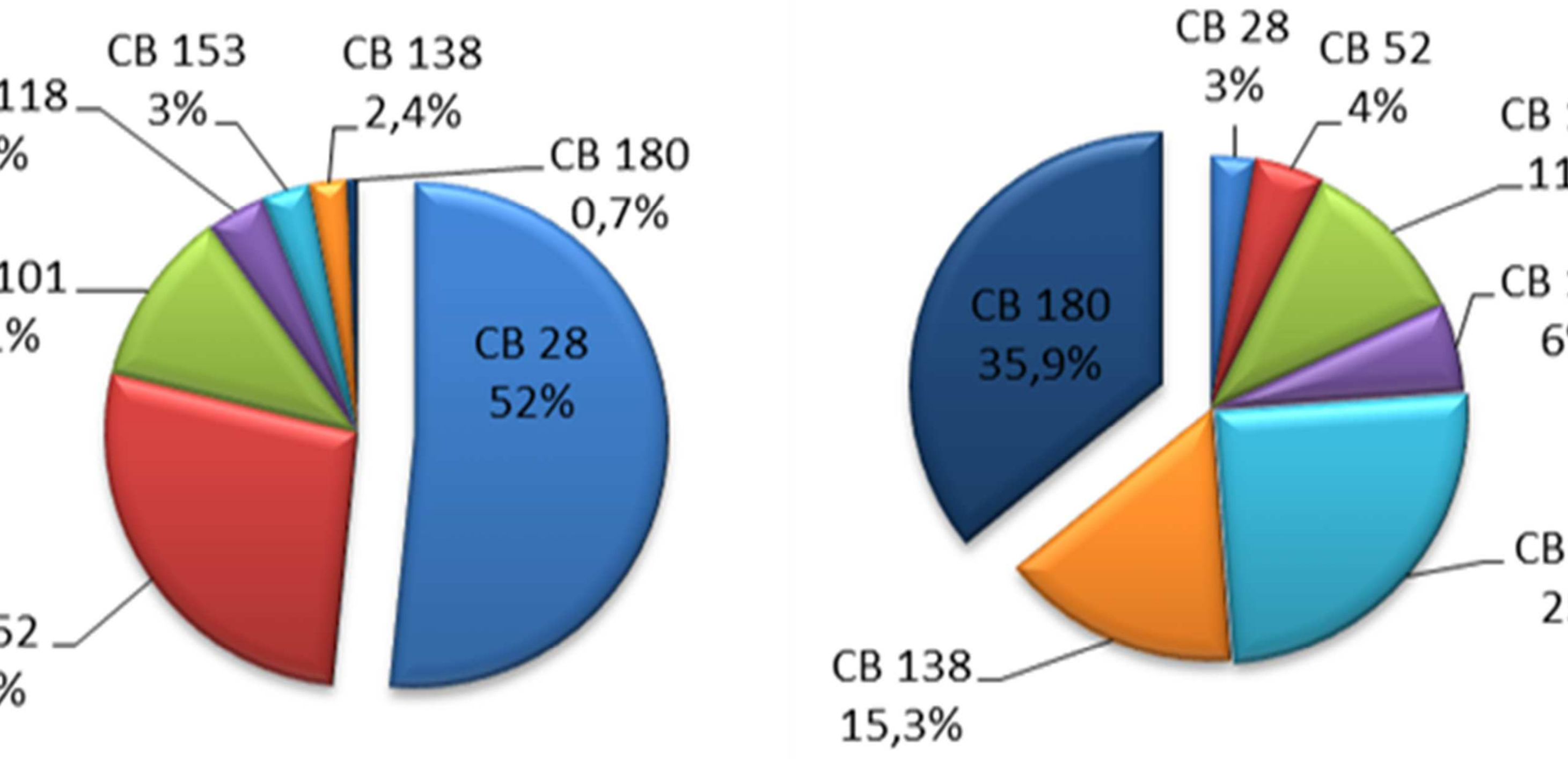

$\mathrm{C}_{\text {free }}, \mathrm{BB03}$ 
chemical activity, sum 7 PCBs

$6 \quad 1, \mathrm{E}-05 \quad 1, \mathrm{E}-04 \quad 1, \mathrm{E}-03 \quad 1, \mathrm{E}-02 \quad 1, \mathrm{E}-01 \quad 1, \mathrm{E}+00$

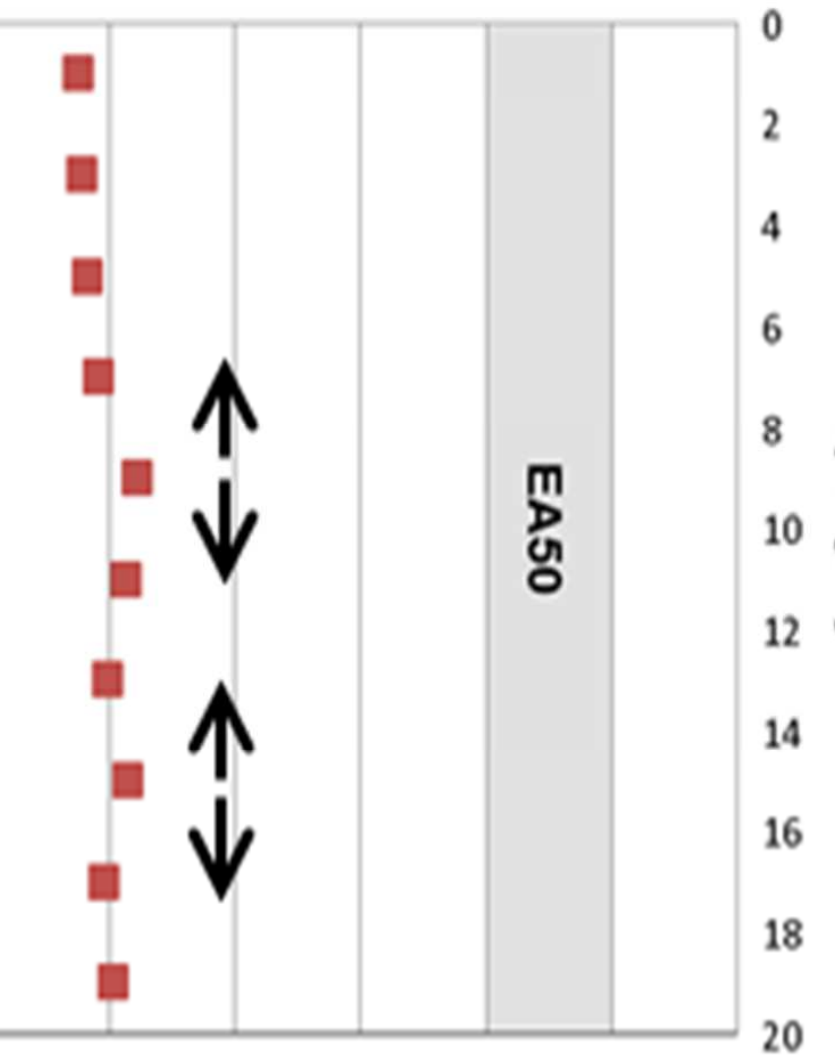

305

chemical activity, sum 7 PCBs

605

chemical activity, sum 7 PCBs
$1, \mathrm{E}-07 \quad 1, \mathrm{E}-06 \quad 1, \mathrm{E}-05 \quad 1, \mathrm{E}-04 \quad 1, \mathrm{E}-03 \quad 1, \mathrm{E}-02 \quad 1, \mathrm{E}-01 \quad 1, \mathrm{E}+00$

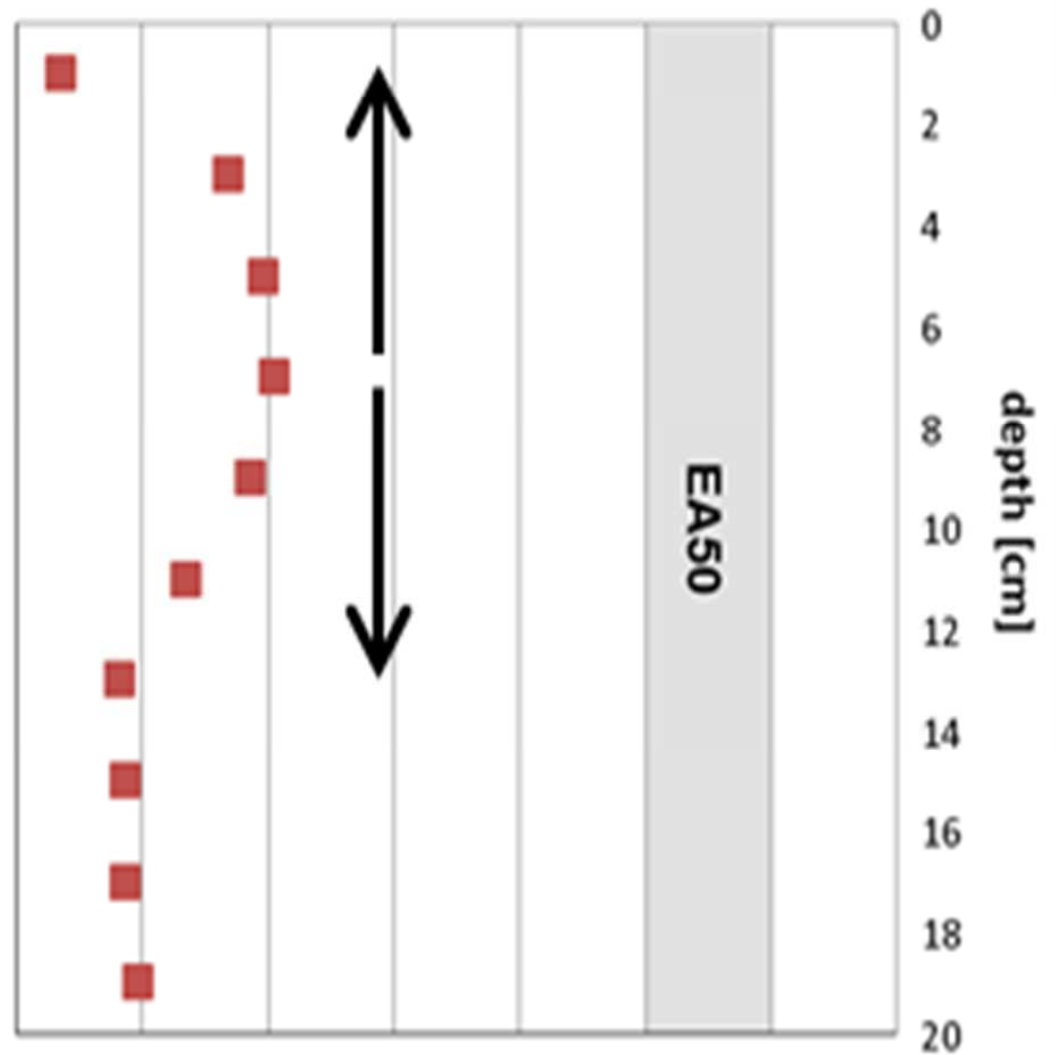

$1, \mathrm{E}-07 \quad 1, \mathrm{E}-06 \quad 1, \mathrm{E}-05 \quad 1, \mathrm{E}-04 \quad 1, \mathrm{E}-03 \quad 1, \mathrm{E}-02 \quad 1, \mathrm{E}-01 \quad 1$

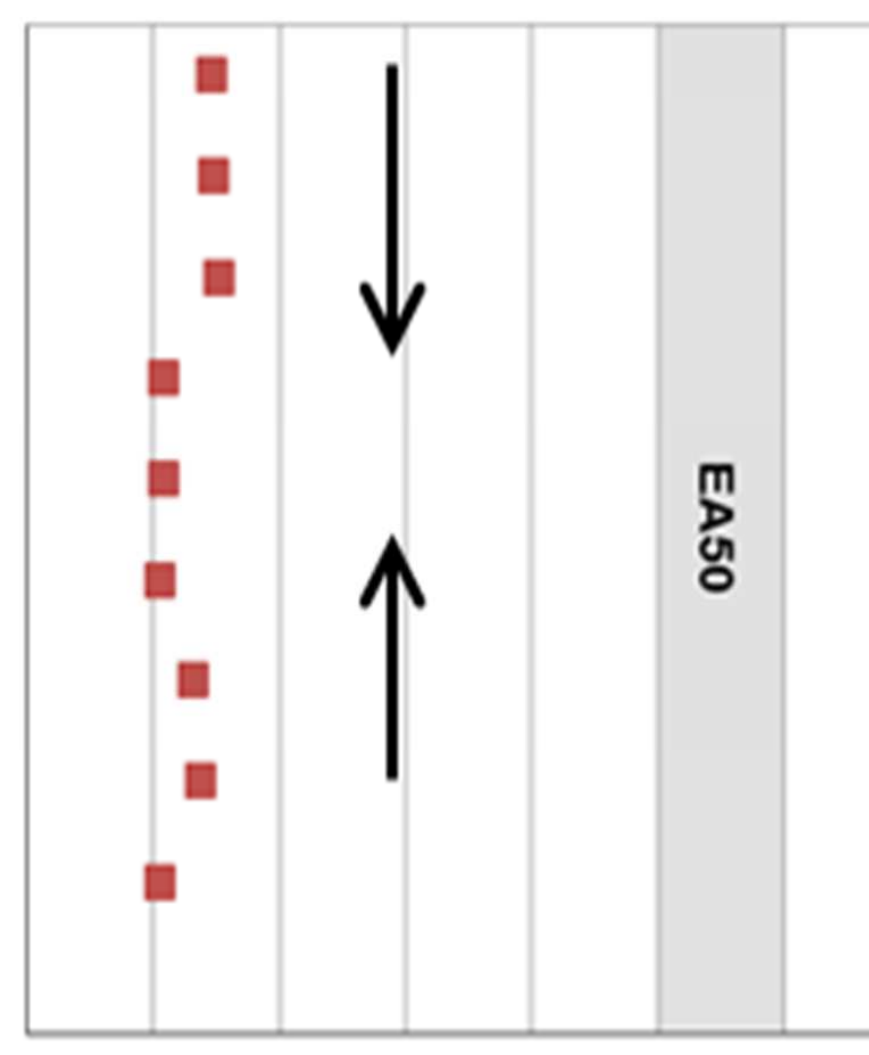




\section{Highlights}

2 - The baseline toxicity of the PCB mixture was below lethality at all sampling sites

- Expressed as chemical activity - higher chlorinated PCBs contributed most to

4 exposure

5

- The sediment was assumed to act as a sink for PCBs in some individual cases

6 - Sorption capacity/sorptive strength of sediments for PCBs revealed regional 7 differences 